\section{AEC \\ RESEARCH \\ and}

DEVELOPMENT

REPORT
BNWL-70

$60-$

\title{
ANALOG COMPUTER METHODS FOR PARAMETER OPTIMIZATION
}

JUNE, 1965
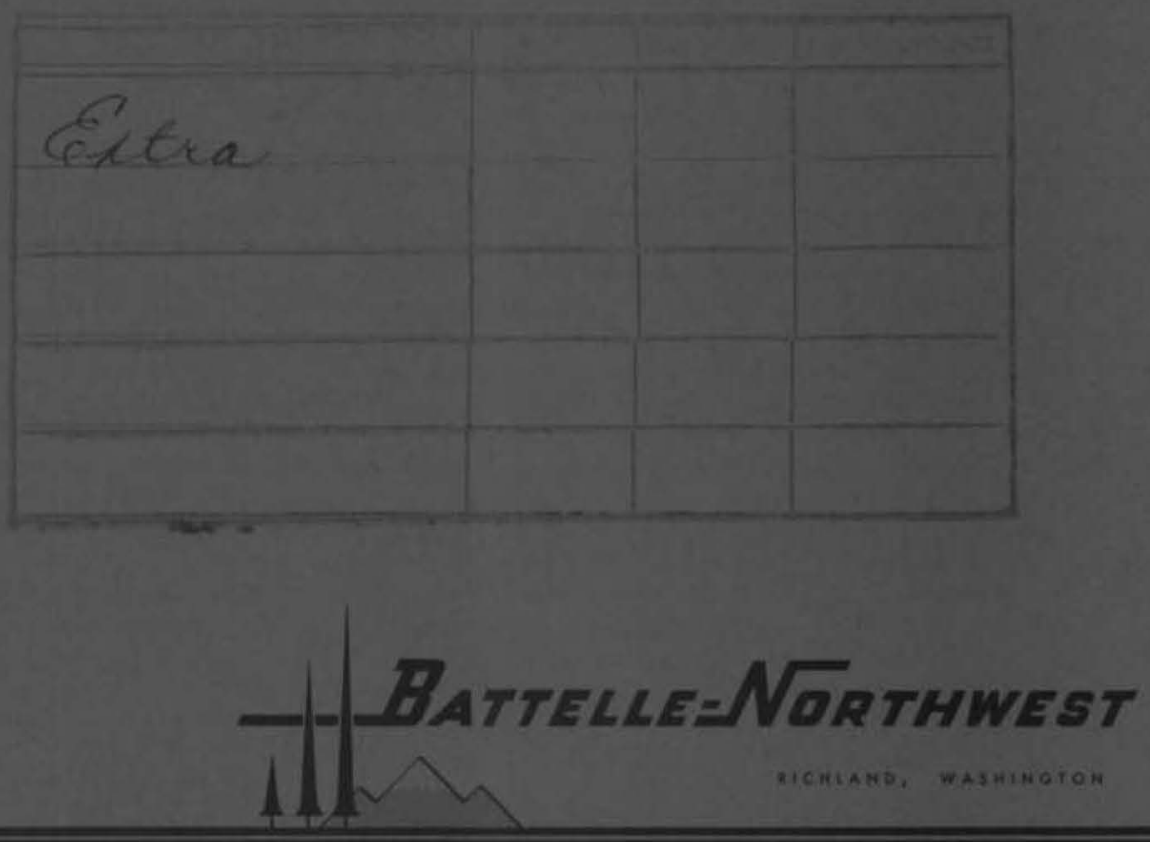

PACIFIC NORTHWEST LABORATORY operated by BATTELLE MEMORIAL INSTITUTE 


\title{
LEGAL NOTICE
}

This report was prepared as an account of Government sponsored work. Neither the United States, nor the Commission, nor any person acting on behalf of the Commission:

A. Makes any warranty or representation, expressed or implied, with respect to the accuracy, completeness, or usefulness of the information contained in this report, or that the use of any information. apparatus, method, or process disclosed in this report may not infringe privately owned rights; or

B. Assumes any liabilities with respect to the use of, or for damages resulting from the use of any information, apparatus, method, or process disclosed in this report.

As used in the above, "person acting on behalf of the Commission" includes any employee or contractor of the Commission, or employee of such contractor, to the extent that such emplayee or contractor of the Commission, or employee of such contractor prepares, disseminates, or provides access to, any information pursuant to his employment or contract with the Commission, or his employment with such contractor.

\author{
PACIFIC NORTHWEST LABORATORY \\ RICHLAND, WASHINGTON \\ operated by \\ BATTELLE MEMORIAL INSTITUTE
}

for the

UNITED STATES ATOMIC ENERGY COMMISSION UNDER CONTRACT AT(45-1)-1830 
BNWL -70

UC-32, Mathematics and Computers

ANALOG COMPUTER METHODS

FOR PARAMETER OPTIMIZATION

HFRT UKFESTRICTED

QSTRLBZULOS MAUE

By

R. A. Harvey, G. R. Taylor, and $R$. D. Benham

Instrument Research and Development

Physics and Instruments

June, 1965 


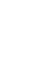

更

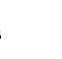

- 
TABLE OF CONTENTS

I. INTRODUCTION . . . . . . . . . . . . . . . . . . . . . . . 1

II. TWO-PARAMETER OPTIMIZATION OF A FIRST ORDER

DIFFERENTIAL EQUATION . . . . . . . . . . . . . . . . . 2

A. Description of Example. . . . . . . . . . . . . . . . . . 2

B. Performance Measures. . . . . . . . . . . . . . . . . . 3

C. Manual Parameter Adjustments . . . . . . . . . . . . . . 4

D. Automatic Optimization of $\mathrm{P}_{2}$. . . . . . . . . . . . . . . . 4

E. Automatic Optimization of $\mathrm{P}_{1}$ and $\mathrm{P}_{2}$. . . . . . . . . . . . . . . . . 6

F. Comments. . . . . . . . . . . . . . . . . . . . . . . . 7

III. EXTRACTION COLUMN: STEADY-STATE MODEL FITTING. . . 8

A. Description of Example. . . . . . . . . . . . . . . . . . 8

B. Performance Measure . . . . . . . . . . . . . . . . . . 10

C. Semiautomatic Optimization Method . . . . . . . . . . . . 12

IV. STEADY-STATE: RANDOM OPTIMIZATION . . . . . . . . . . . 12

A. Performance Measure . . . . . . . . . . . . . . . . . . 12

B. Automatic Optimization Method . . . . . . . . . . . . . . 15

C. Results. . . . . . . . . . . . . . . . . . . . . . . . 17

D. Comments. . . . . . . . . . . . . . . . . . 20

V. RIVER FLOW: DYNAMIC MODEL FIT TING . . . . . . . . . . 20

A. Process Description. . . . . . . . . . . . . . . . . . 20

B. Performance Measure . . . . . . . . . . . . . . . . . . 22

C. Automatic Optimization Methods. . . . . . . . . . . . . . 23

D. Results . . . . . . . . . . . . . . . . . . . . . . 26

E. Conclusion . . . . . . . . . . . . . . . . . . . . . . 29

VI. REFERENCES . . . . . . . . . . . . . . . . . . . . . . 30 


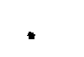

,

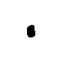




\section{ANALOG COMPUTER METHODS FOR PARA METER OPTIMIZATION}

\section{INTRODUCTION}

Franke, Gordon, and Clymer ${ }^{(1)}$ and Bekey $(2,3)$ give a comprehensive review of optimization literature. In addition, Lee, (4) Steinmetz, (5) and Witsenhausen ${ }^{(6)}$ have reported on computer mechanization of Pontryagin's maximum principle. This report describes techniques for parameter optimization with analog computers where it is desired to determine the the best parameters of a mathematical model.

The selection of optimum values implies the use of a performance index for deterrnining when one set of parameter values is better than another. The performance indices used are listed below and a re illustrated with examples.

1. The error at the end of the computing period

2. The integral of the error

3. The integral of the error squared

4. A general quadratic equation (where the process equation is the performance index)

5. The partial derivative of the error squared integral with respect to each parameter in the mathematical model.

In general, manual optimization techniques a re implemented for parameter optimization studies using analog computers. The time required for determination of the optimum parameters increases rapidly with the number of parameters. Most two parameter (interacting) problems require from 2 to $5 \mathrm{~min}$ for determining optimum values. Three parameter problems may require over $15 \mathrm{~min}$, and four parameter problems may require $2 \mathrm{hr}$ or more. Problems which have several interrelated parameters can become time consuming, particularly if a large number of different conditions a re to be explored. A natural extension to manual parameter optimization is that of programming the computer to seek the optimum values automatically. 
The examples given in this report describe both manual and automatic techniques for analog computer parameter optimization studies.

II. TWO PARAMETER OPTIMIZA TION OF A FIRST ORDER

DIFFERENTIA L EQUATION

\section{A. Description of Example}

A problem that involves the automatic optimization of two parameters in a first order differential equation was chosen to demonstrate a capability of the EASE 2133 iterative analog computer. Equation (1) defines $A_{1}$ and $\mathrm{A}_{2}$, the constants used in the generation of the model waveform whose solution is given by Equation (2).

$$
\frac{d y m}{d t}+A_{1} y=A_{2} U(t)
$$

where $U(t)$ is a unit step function starting at time $=0$.

$$
y_{m}=\frac{A_{2}}{A_{1}}\left(1-e^{-A_{1} t}\right)
$$

The problem is to generate a similar waveform which solves Equation (3) automatically, for values of $P_{1}$ and $P_{2}$ equal to $A_{1}$ and $A_{2}$.

$$
\frac{d y}{d t}+P_{1} y=P_{2} U(t)
$$

The solution to Equation (3) is

$$
y=\frac{P_{2}}{P_{1}}\left(1-e^{-P_{1} t}\right)
$$

Figure 1 illustrates the comparison of the trial waveform $y$ with the model waveform $\mathrm{Y}_{\mathrm{m}}$ when $\mathrm{P}_{1}$ equals $\mathrm{A}_{1}$ and $\mathrm{P}_{2}$ is allowed to vary. The trial waveform $\mathrm{y}$ is the same as $\mathrm{y}_{\mathrm{m}}$ when $\mathrm{P}_{2}$ equals $\mathrm{A}_{2}$. If $\mathrm{P}_{2}$ is greater than $\mathrm{A}_{2}$, the trial waveform has the proper time constant but is higher in magnitude than $\mathrm{y}_{\mathrm{m}}$. 


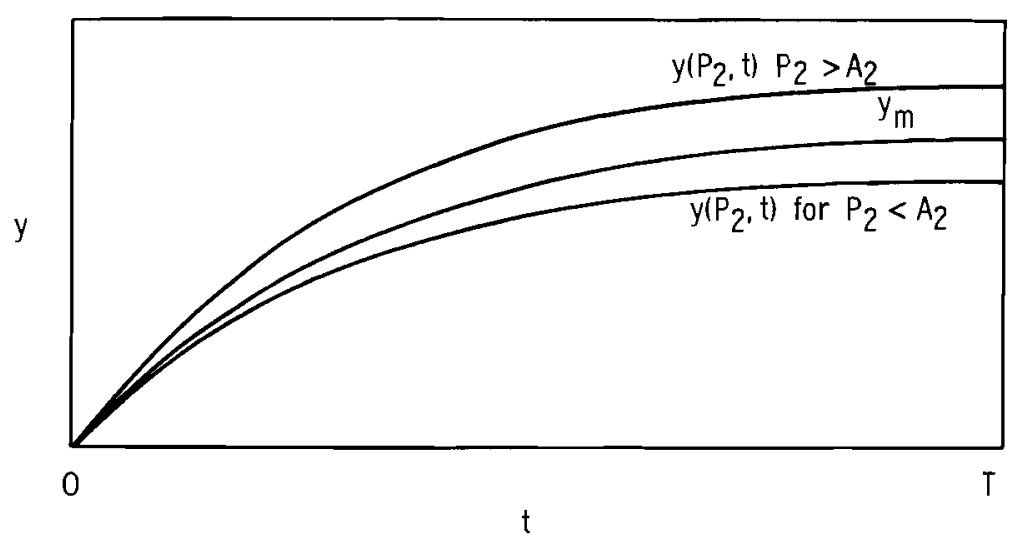

FIGURE 1

Comparison of $\mathrm{y}$ with $\mathrm{y}_{\mathrm{m}}$ for $\mathrm{P}_{1}=\mathrm{A}_{1}$

Figure 2 gives a comparison of $\mathrm{y}$ with $\mathrm{y}_{\mathrm{m}}$ when $\mathrm{P}_{2}$ equals $\mathrm{A}_{2}$ and $\mathrm{P}_{1}$ is allowed to vary. When $P_{1}$ is equal to $A_{1}, y$ is exactly equal to $y_{m}$. If $P_{1}$ is less than $A_{1}$, the trial waveform $y$ has a higher magnitude and longer time-constant than $\mathrm{y}_{\mathrm{m}}$. If $\mathrm{P}_{1}$ is greater than $\mathrm{A}_{1}$, the trial waveform has a shorter time-constant and lower magnitude than $\mathrm{y}_{\mathrm{m}}$.

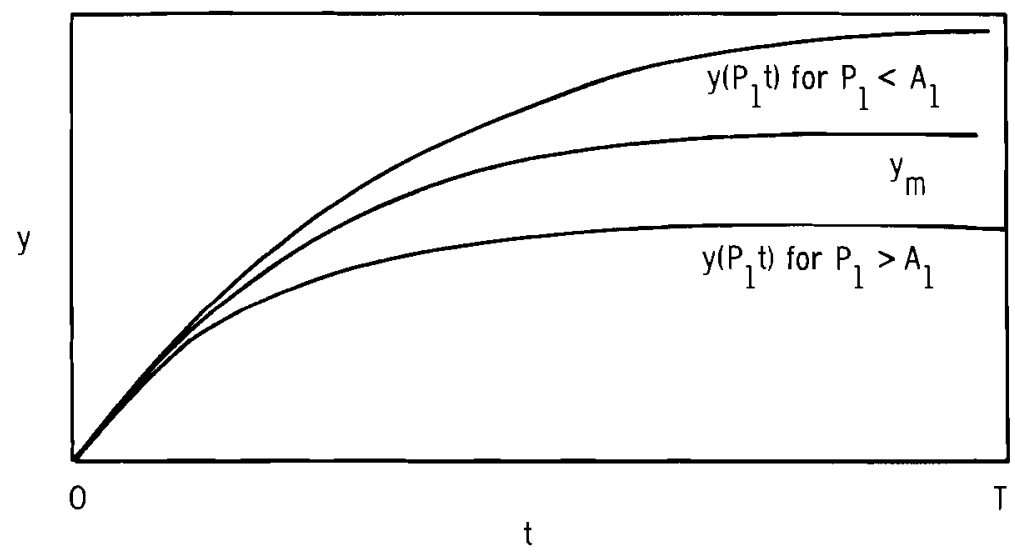

$\underline{\text { FIGURE } 2}$

Comparison of $\mathrm{y}$ with $\mathrm{y}_{\mathrm{m}}$ for $\mathrm{P}_{2}=\mathrm{A}_{2}$

B. Performance Measures

The techniques for determining the optimum values $\mathrm{P}_{1}$ and $\mathrm{P}_{2}$ are presented in three parts. The first part describes a manual method for optimizing the parameters by visual inspection of the best fit of curve $\mathrm{y}$ to $\mathrm{y}_{\mathrm{m}}$. 
The second part shows the simple concept of a final value solution for optimizing the parameter $\mathrm{P}_{2}$ where the performance index is the error at the end of the computing period. The value of the parameter $P_{1}$ is equal to $\mathrm{A}_{1}$ for this case.

The third part of the example illustrates the analog computer techniques for automatically optimizing the parameters $\mathrm{P}_{1}$ and $\mathrm{P}_{2}$. The performance index used for adjusting $P_{1}$ is the integral of the error between the model curve and the calculated curve. The performance index for $\mathrm{P}_{2}$ is again the error at the end of the computing cycle.

\section{Manual Parameter Adjustments}

Parameters $\mathrm{P}_{1}$ and $\mathrm{P}_{2}$ can be adjusted manually to equal $\mathrm{A}_{1}$ and $\mathrm{A}_{2}$ by comparing waveforms, making trial manual adjus tments of $\mathrm{P}_{1}$ and $\mathrm{P}_{2}$, and again comparing waveforms. This trial and error procedure requires a number of iterations to converge to the best solution. From observation of an oscilloscope display of both $y$ and $y_{m}$ simultaneously, manual adjustment of the parameters is straightforward. If the repetitive solution rate is $10 /$ sec or higher, manual adjustment of $\mathrm{P}_{1}$ and $\mathrm{P}_{2}$ can be made to converge on the values of $A_{1}$ and $A_{2}$ in approximately $15 \mathrm{sec}$. Arbitrary changes in $A_{1}$ and $A_{2}$ result in relatively rapid convergence with only two parameters; three parameters require a considerably longer time by manual methods.

D. Automatic Optimization of $\mathrm{P}_{2}$

Before automatic optimization can be programmed on the computer, one or more performance measures are required which permit information to be fed back to correct the parameter values. Figure 1 illustrates that at time $\mathrm{T}$ (end of computing interval) a positive error exists if $\mathrm{P}_{2}>\mathrm{A}_{2}$ and a negative error exists if $\mathrm{P}_{2}<\mathrm{A}_{2}$ when $\mathrm{P}_{1}=\mathrm{A}_{1}$. This error at time $\mathrm{T}$ is taken as the performance measure for adjusting parameter $\mathrm{P}_{2}$ for the next iterative computation.

Figure 3 shows the analog computer program for automatic optimization of $\mathrm{P}_{2}$. The symbol $\mathrm{M}$ (Integrators 8,0 , and 26) indicates that the 


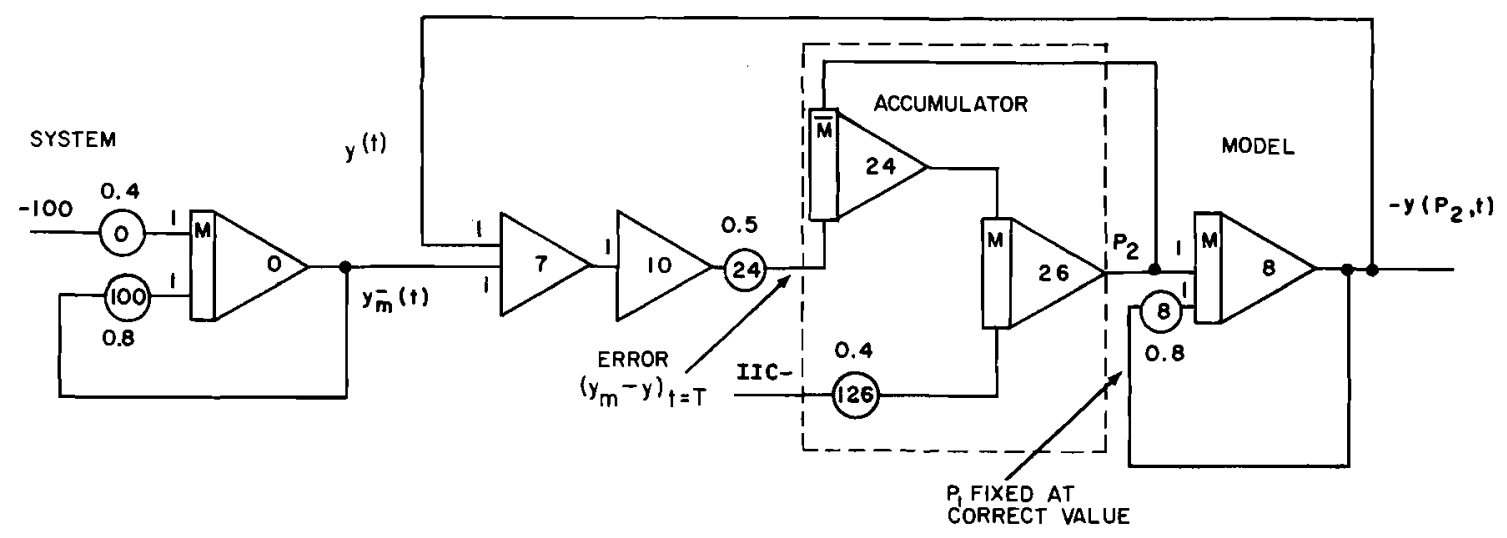

FIGURE 3

Analog Circuit for the Automatic Optimization of $\mathrm{P}_{2}$

timing cycle is controlled by the master timer and the $\bar{M}$ (Integrator 24) indicates complimentary operation. (Amplifier 24 is in the IC mode when 8,0 , and 26 are computing and in compute when 8,0 , and 26 are in IC.) Integrator 0 with Pots 0 and 100 generate the model waveform $\mathrm{y}_{\mathrm{m}}$. The waveform $\mathrm{y}$ is compared with $\mathrm{y}_{\mathrm{m}}$ in Amplifier 7 and is applied to the accumulator circuit (Integrators 24 and 26), the output of which is the value of $\mathrm{P}_{2}$. The error between $\mathrm{y}$ and $\mathrm{y}_{\mathrm{m}}$ at the end of the computing interval is us ed to readjust the value of $\mathrm{P}_{2}$. When $\mathrm{P}_{2}$ approaches the correct value, the error approaches zero. The rate of convergence to the correct solution is determined by the proportional gain (Pot 24) of the control loop.

The usual concepts of feedback stabilization are prevalent in the control loop. The feedback loop phase shift includes the time delay of one iteration and the process time delay. As the loop gain is increased (Pot $24)$, a point of instability is reached where the entire solution oscillates and diverges from the correct solution. For the conservative setting of 0.5 for Pot 24 and an iteration rate of 10 solutions per second, the system converges to the correct value of $\mathrm{P}_{2}$ in about $1 \mathrm{sec}$.

If Pots 8 and 100 are set at different values, the resulting y converges to $\mathrm{y}_{m}$ at time $\mathrm{T}$, but the curves do not match over the rest of the computing interval. The IIC voltage sets the initial condition for the first iteration only. 


\section{E. Automatic Optimization of $\mathrm{P}_{1}$ and $\mathrm{P}_{2}$}

The performance measure for the automatic optimization of $\mathrm{P}_{1}$ was chosen as the integral of the error between $\mathrm{y}$ and $\mathrm{y}_{\mathrm{m}}$ over the computing interval. Figure 4 shows the comparison when $\mathrm{y}$ is constrained to equal $\mathrm{y}_{\mathrm{m}}$

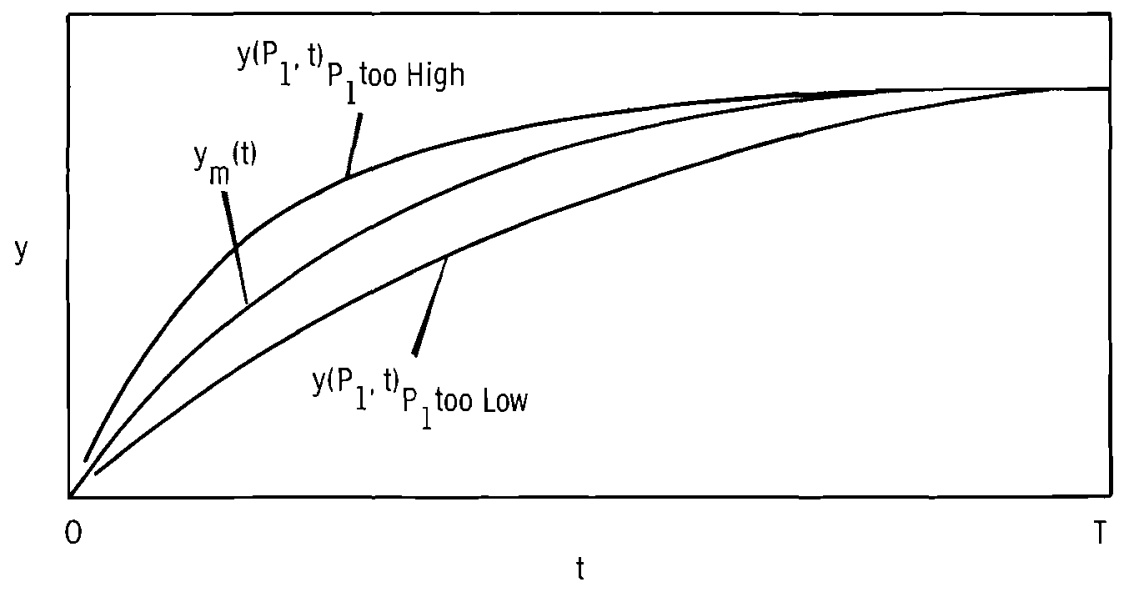

FIGURE 4

Comparison of $y(t)$ with $\mathrm{y}_{\mathrm{m}}(\mathrm{t})$ when $y(T)=y_{m}(T)$

at the end of the computing interval. If $\mathrm{P}_{1}$ is high, the time constant is too short and $\mathrm{y}$ is always greater than $\mathrm{y}_{\mathrm{m}}$. When $\mathrm{P}_{1}$ is low, a long time constant for $\mathrm{y}$ exists and $\mathrm{y}$ is always less than $\mathrm{y}_{\mathrm{m}}$.

Mechanization of the automatic optimization of $\mathrm{P}_{1}$ and $\mathrm{P}_{2}$ is shown in Figure 5. The $\mathrm{P}_{2}$ optimizing circuit is the same as in Figure 3 . The $P_{1}$ pot (Pot 8 in Figure 3 ) is replaced by a multiplier with $P_{1}$ as an input from the accumulator circuit (Integrators 3 and 4). The error signal from Amplifier 7 and Pot 2 is integrated (Integrator 2) and applied to the accumulator circuit. Each or both of the optimization control loops can be made to oscillate and become unstable by using high loop gains. Also, because of the interaction between the two loops, the entire system can go unstable if the $\mathrm{P}_{1}$ loop gain is too high. It was found that for stability reasons the control loop which a utomatically adjusts $\mathrm{P}_{1}$ must converge at a slower rate than the $\mathrm{P}_{2}$ control loop. The setting shown on Pot 2 , results in relatively slow convergence for $\mathrm{P}_{1}$ (about $5 \mathrm{sec}$ ) when $\mathrm{A}_{1}$ and $\mathrm{A}_{2}$ are changed. 


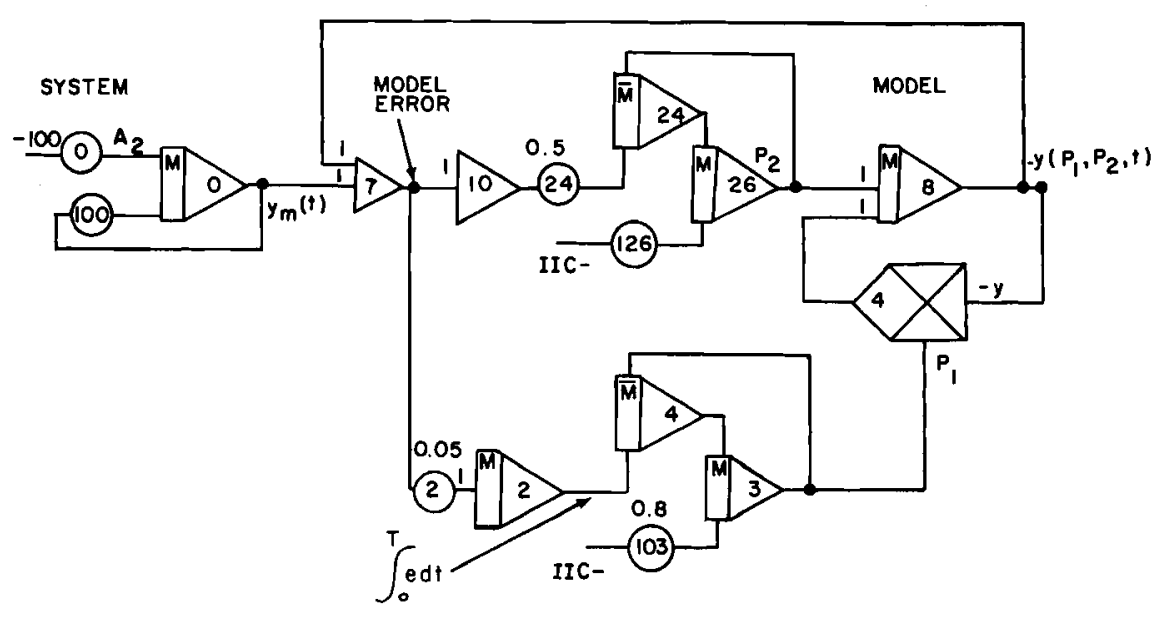

FIGURE 5

Analog Circuit

for the Automatic Optimization of $\mathrm{P}_{1}$ and $\mathrm{P}_{2}$

F. Comments

This example of parameter optimization is significant for several reasons. Simple techniques can be used with iterative analog computers provided the parameter influence coefficients $\frac{\partial f_{1}}{\partial P_{1}}$ and $\frac{\partial f_{2}}{\partial P_{2}}$ (where $f_{1}$ and $f_{2}$ are the performance measures) do not change sign. Ordinary feedback techniques can be used with no particular need for circuit development. On this example two performance indices were used: (1) the error at the end of the computing period, and (2) the integral of the error over the computing integral with the constraint that the error be low enough at the end of the computing cycle to insure stability of this optimization scheme. Other performance indices could have been used. For example, both parameters could be optimized by using the integral of the error squared over the computing interval. The quadratic nature of the error-squared-integral, however, results in additional difficulties discussed in another example. Selection of a suitable performance index leaves considerable room for creative thinking on many problems. The particular indices used in this example were selected to provide a simple and practical form of solution and to permit application of familiar servomechanism feedback techniques. 
III. EXTRACTION COLUMN: STEADY-STATE MODEL FITTING

A. Description of Example

Pulsed extraction columns are used at Hanford for extracting uranyl nitrate from an organic stream into a dilute nitric acid stream. Figure 6 shows aqueous feed entering at the top of the column. The organic, uraniumbearing fluid is introduced at the bottom of the column. As the two streams flow counter-currently, the uranium is stripped from the organic phase into the aqueous phase. The stripped organic solution leaves from the top of the column while the product aqueous leaves from the bottom. The pulsing action in association with the perforated internal column plates helps to increase the area of the dispersed aqueous phase for mass transfer between the phases.

A study aimed at an automatic optimization of a series of extraction columns was performed by Wilburn. ${ }^{(7)}$ Data were obtained for steady-state conditions on total uranium concentration as a function of column height. Smoothed data gathered for a typical operating condition are shown in Figure 7. Several mathematical models were derived to describe the operation of the column. The equations for each proposed model were simulated on the analog computer. $(8,9)$ The equations that most closely represented the data given above are:

$$
\begin{aligned}
& \frac{\mathrm{dc}}{\mathrm{dz}}=-0.1005 \mathrm{~K}_{\mathrm{Ox}}{ }^{\mathrm{a}}\left(\mathrm{c}_{\mathrm{x}}-\mathrm{c}_{\mathrm{x}}{ }^{*}\right) \\
& c_{\mathrm{xO}}=77.39 \\
& c_{\text {yo }}=61.79 \\
& \frac{\mathrm{dc}}{\mathrm{dz}}(\mathrm{o})=0.0 \\
& \left.\frac{\mathrm{d}^{2} \mathrm{c} y}{\mathrm{dz}}=-\frac{1}{\mathrm{E}(1-\mathrm{y})}\left[11.14 \frac{\mathrm{dc}}{\mathrm{dz}}+\mathrm{K}_{\mathrm{ox}}{ }^{\mathrm{a}(\mathrm{c}} \mathrm{x}-\mathrm{c}_{\mathrm{x}}{ }^{*}\right)\right]
\end{aligned}
$$




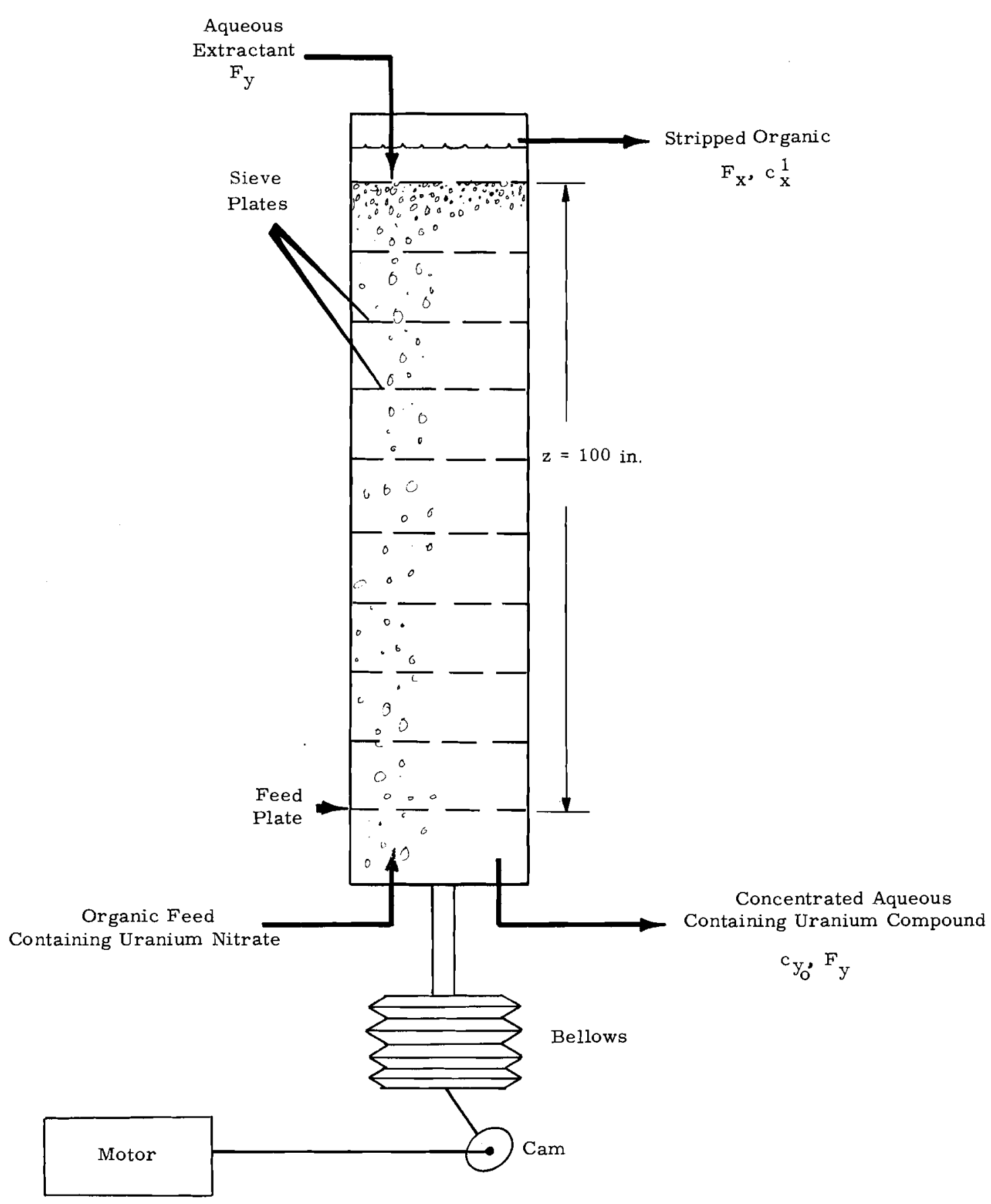

FIGURE 6

Pulsed Extraction Column 


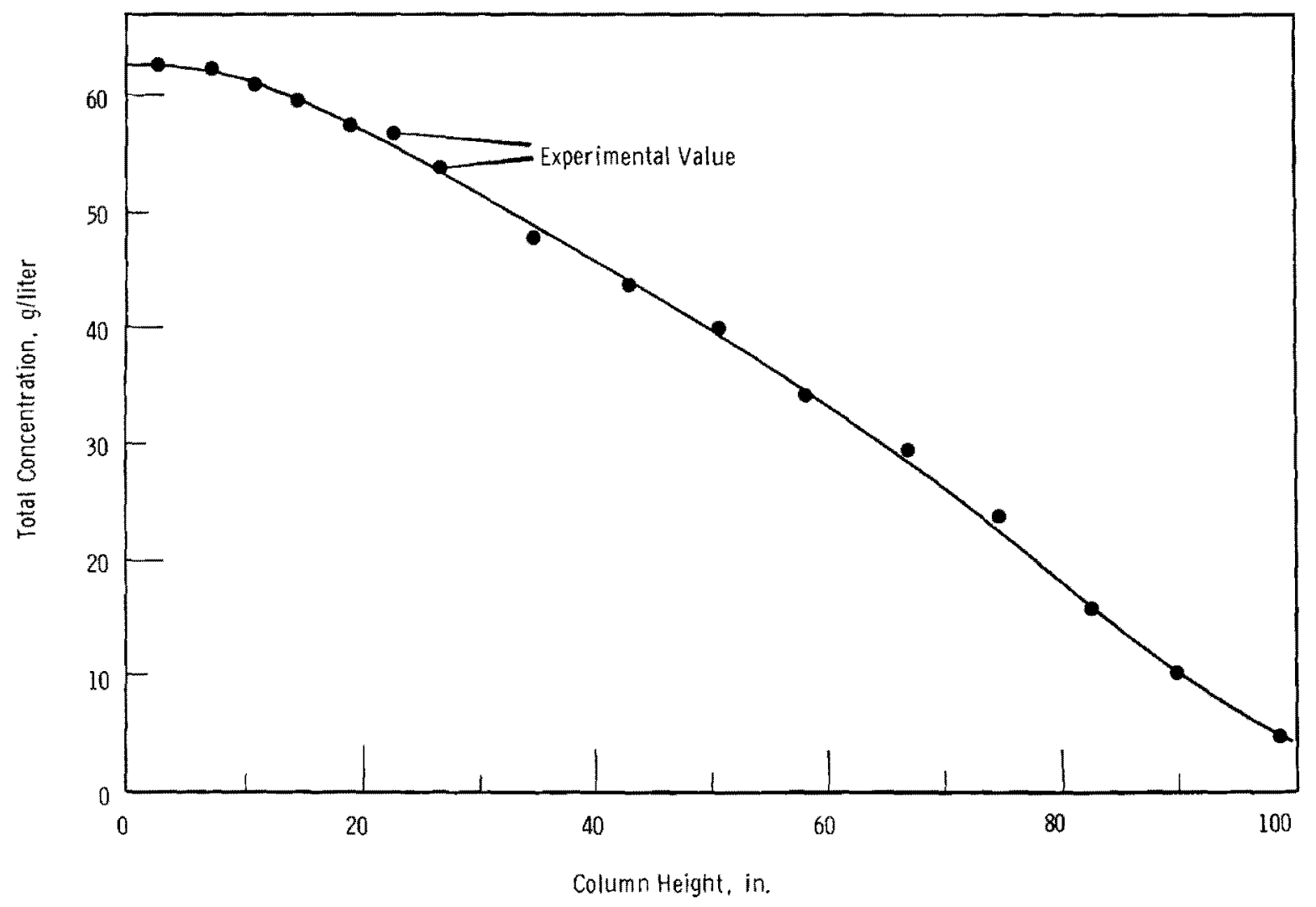

FIGURE 7

Typical Total Uranium Concentration Data as a Function of Column Height

$$
\begin{aligned}
\epsilon & =0.7246 \sqrt{0.0121(z+1.7626)} \exp -0.0121(z+1.7626) \\
c_{x}^{*} & =f\left(c_{y}\right)
\end{aligned}
$$

\begin{tabular}{|c|c|}
\hline$c_{y}$ & $c_{x}^{*}$ \\
\hline 0 & 0 \\
\hline 7. 14 & 0.98 \\
\hline 11. 9 & 3.1 \\
\hline 40.0 & 34.0 \\
\hline 71.0 & 61.5 \\
\hline 95.5 & 78.5 \\
\hline 100.0 & 80.0 \\
\hline
\end{tabular}


where

$$
\begin{aligned}
c_{y}= & \text { concentration of uranium in aqueous phase } \\
c_{x}= & \text { concentration of uranium in organic phase } \\
\varepsilon= & \text { volume fraction of organic at any point in the column } \\
K_{\mathrm{Ox}}= & \text { overall coefficient of mass transfer based on organic } \\
& \text { phase } \\
\mathrm{a}= & \text { interfacial area per column volume } \\
\mathrm{E}_{\mathrm{y}}= & \text { longitudinal dispersion coefficient in the aqueous } \\
& \text { phase. }
\end{aligned}
$$

B. Performance Measure

It is desired to determine the values of $\mathrm{E}_{\mathrm{y}}$ and $\mathrm{K}_{\text {ox }} \mathrm{a}^{\mathrm{a}}$ that most closely fit the experimental data. The difference between the calculated value of the uranium and the experimental data was used as a measure of the performance of the system of equations. To avoid confusion arising from the sign, this difference was squared and integrated along the column. The values of $\mathrm{E}_{\mathrm{y}}$ and $\mathrm{K}_{\mathrm{Ox}}$ a that result in a minimum of the error squared integral correspond to the best fit of the model to the data. The equations necessary for performing the operation are listed below:

$$
\begin{aligned}
W_{f g} & =f(z) \\
W & =\epsilon c_{x}+(1-\epsilon) c_{y} \\
I & =\int_{0}^{100}\left(W_{f g}-W\right)^{2} d z
\end{aligned}
$$

where

$$
\begin{aligned}
W_{f g} & =\text { uranium concentration as measured experimentally } \\
W & =\text { uranium concentration calculated by model } \\
\mathrm{I} & =\text { error criterion. }
\end{aligned}
$$




\section{Semiautomatic Optimization Method}

This type of problem is solved by a conventional analog computer (EASE 1132) with repetitive operation by making a parameter search and plotting the error surface (Figure $C^{\prime}$ as a function of the parameter values. The error cross sections shown in Figure 8 were plotted a utomatically. Each point represents evaluation of the performance function and each cross section is evaluated for a constant value of $\mathrm{E}_{\mathrm{y}}$. Error cross sections are plotted until an overall minimum of the performance function is found.

Figure 9 presents the program for performing the parameter search. The equations a re programmed so one complete solution is obtained in about $1 \mathrm{sec}$.

One parameter search is mechanized by fixing the value of $\mathrm{E}_{\mathrm{y}}$ (Pot 21) and varying $\mathrm{K}_{\mathrm{Ox}} \mathrm{a}^{\mathrm{a}}$ (Amplifier 66) until a minimum of the error squared integral (Amplifier 29) is realized. The value of $\mathrm{E}_{\mathrm{y}}$ is then changed and $\mathrm{K}_{\mathrm{Ox}}$ a is again allowed to vary until a minimum of the error squared integral is realized. This procedure is repeated until an overall minimum of the error squared integral is found.

A higher value of $\mathrm{K}_{\text {ox }}$ a for each repetitive calculation is produced by using an integrator (A mplifier 41) without reset or hold logic. The error introduced into each calculation is reduced by using a very small input signal $(0.05$ to 0.10$)$ to the integrator.

IV. STEADY-STATE: RANDOM OPTIMIZATION

A. Performance Measure

Parameter optimization for this example is accomplished by determining the values of the variables $\mathrm{x}, \mathrm{y}$, and $\mathrm{z}$ which produce a minimum value of $f(x, y, z)$ in Equation (12).

$$
f(x, y, z)=(x-5)^{2}+(x+y)^{2}+(z-y-x)^{2}+10
$$

While this equation does not necessarily represent a physical system, it was synthesized with the requirement that all variables be quadratic. 


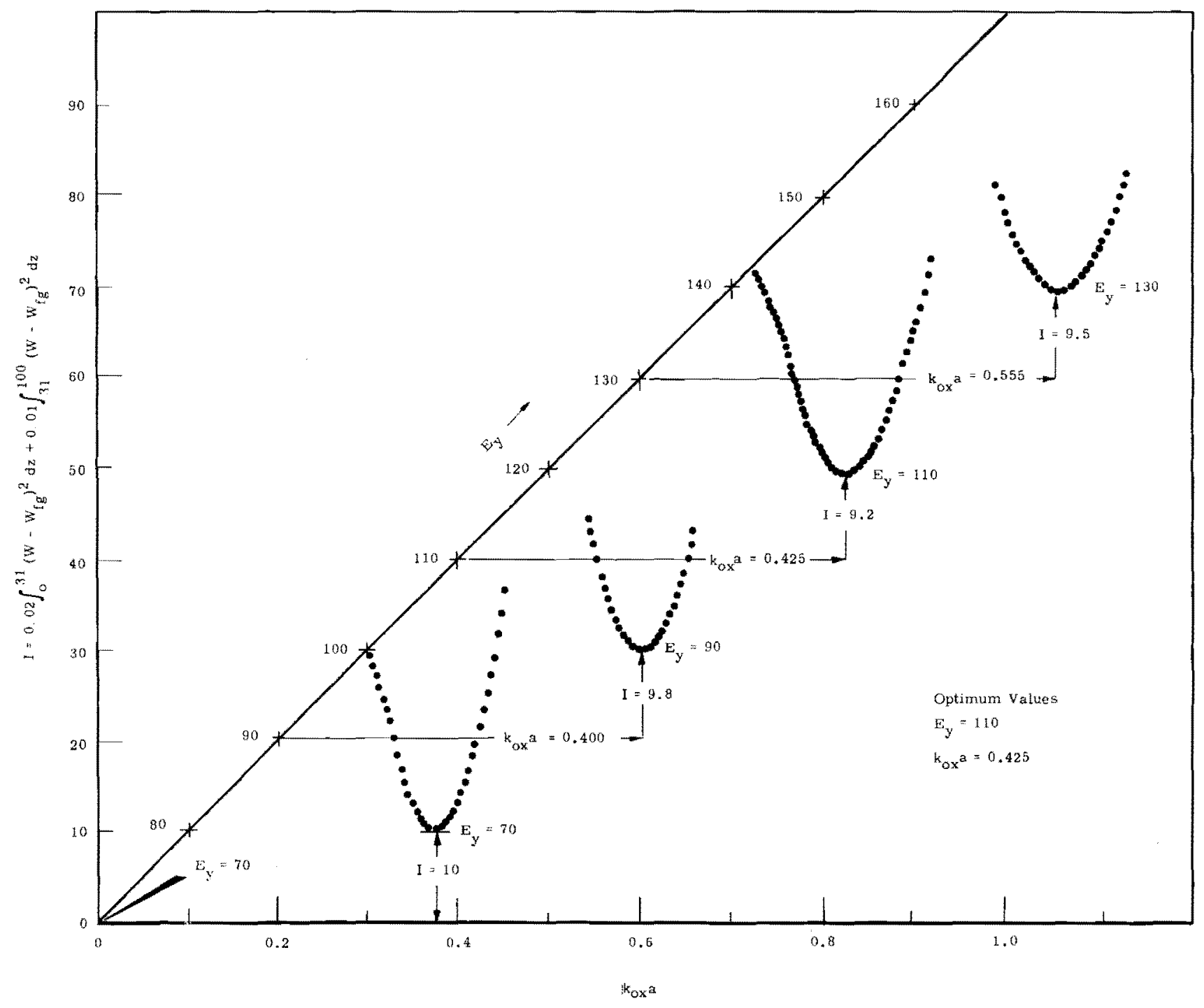

FIGURE 8

Error Surface as Defined by the Error Squared Integral 


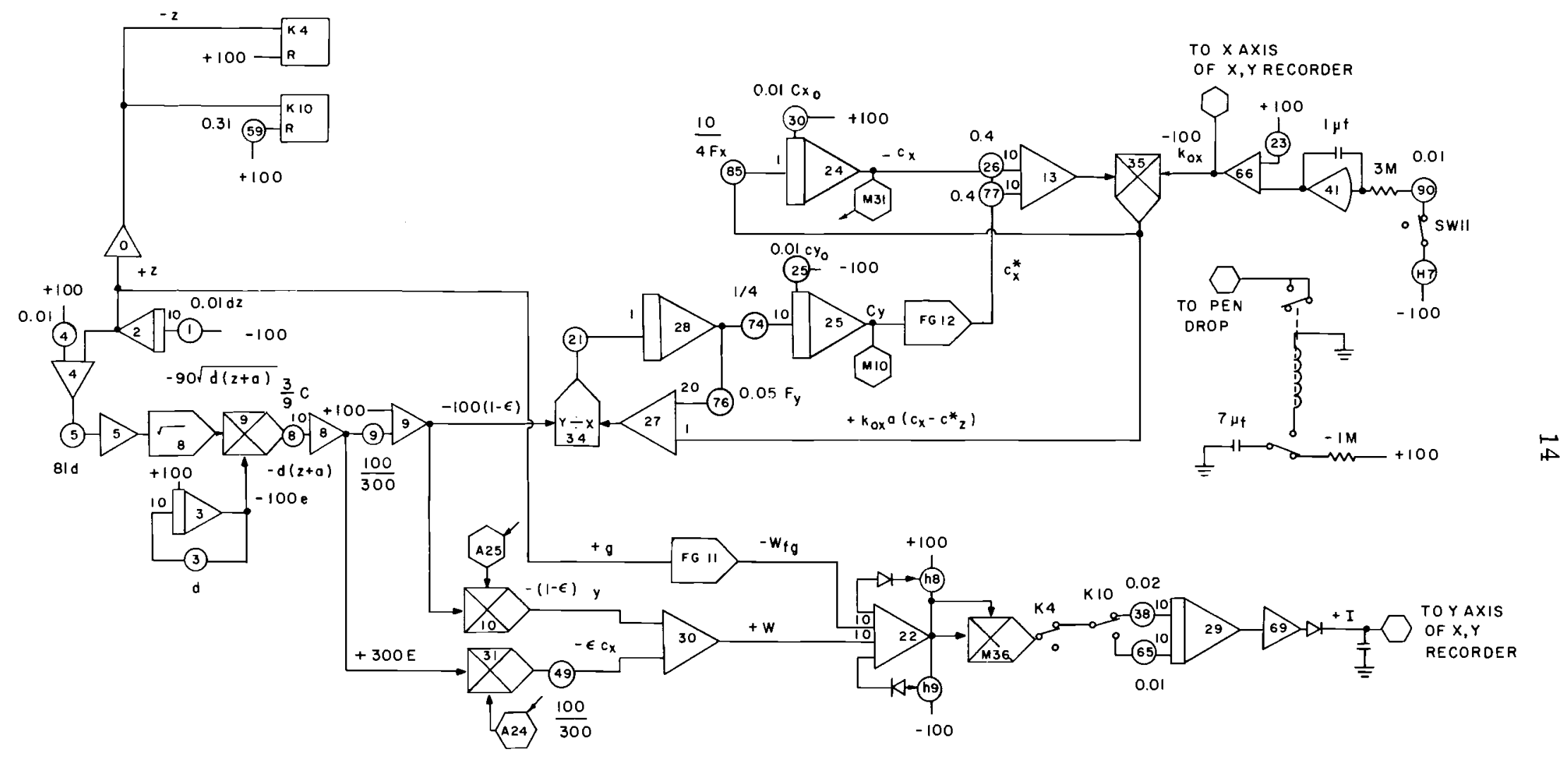

FIGURE 9

Analog Computer Patching Diagram

for Pulsed Extraction Column 
The quadratic form of performance was chosen because it represents an added degree of complication over the first example. The simple, sampled-feedback servo-system of the first example results in an instability at the optimum parameter value if the quadratic performance is used; hence, some other method was needed. The random perturbation method with optimum seeking logic is sufficient for convergence.

\section{B. Automatic Optimization Method}

Optimization by random variation of the parameters, similar to that reported by Munson and Rubin ${ }^{(10)}$ was the method chosen to implement the automatic system. Figure 10 shows the complete analog circuit necessary to perform the automatic parameter optimization. This circuit was used with the EASE 1132 computer which was not initially equipped for iterative operation. Since analog memory was required, the computer was modified by the addition of switches in the connections to the IC relay coils to all integrators to allow the IC relay coils to be connected normally to the computer IC bus or optionally to the unassigned area of the patchboard. By use of a suitable relay circuit, any selected integrators in groups of four could be used to provide the necessary analog memory.

Another requirement for this technique is the availability of a random noise generator for each parameter. Since only one random noise generator was available, its output was recorded sequentially on both channels of a dual channel continuous loop magnetic tape transport using FM recording techniques. Playback from the tape transport provided two additional random noise sources.

The operational logic for the system is tabulated below:

(1) Initial values of $\mathrm{x}, \mathrm{y}$, and $\mathrm{z}$ are selected with Pots 8, 12, and 18 shown in Figure 10. After the computer has been momentarily placed in compute and then to reset, the initial values of $\mathrm{x}, \mathrm{y}, \mathrm{z}$ and $\mathrm{f}(\mathrm{x}, \mathrm{y}, \mathrm{z})$ are stored in memory Integrators 10,11 , 14 , and 15 . 


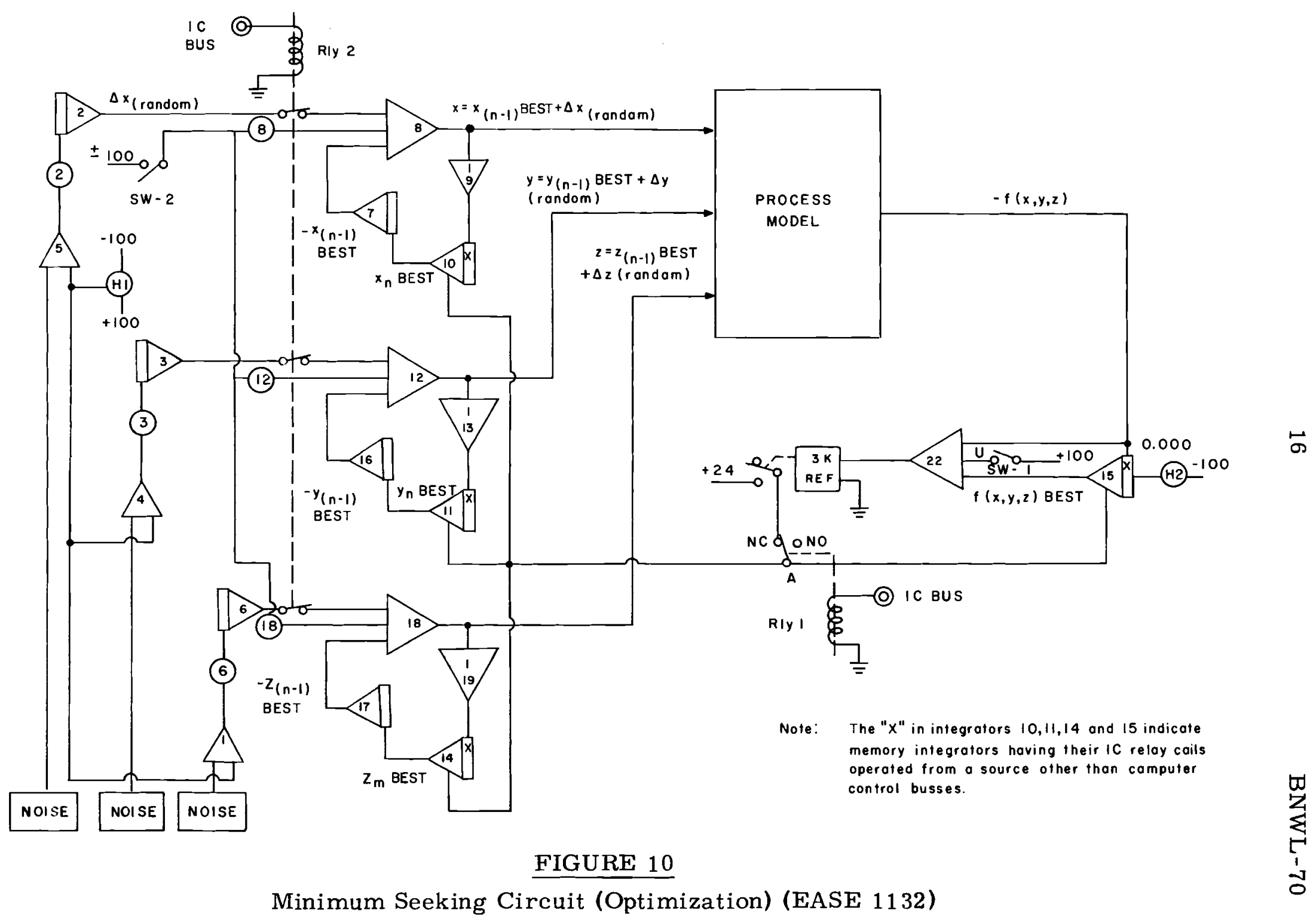


(2) Switches 1 and 2 are changed to the open position while the computer is in reset.

(3) The computer is placed in repetitive mode with the highest repetition rate (about four repetitions per second).

(4) During repetitive operation, the computer alternates automatically between reset and compute modes. Every time the computer returns to reset, random incremental changes of $\Delta x, \Delta y$, and $\Delta \mathbf{z}$ a re taken from Integrators 2,3 , and 6 . The magnitude of the increments is controlled by Pots 2,3 , and 6 . The increments are added to the last best values of $x, y$, and $z$ in Summers 8,12 , and 18 for the next trial computation. The best trial value of each parameter is retained and updated only when a trial produces an improvement in the performance index stored in Memory Integrator 15 . If a trial value of the performance is smaller than the previous best value (Integrator 15), the output of Amplifier 22 goes negative and Differential Relay 1 is energized. This operation closes the IC relays on Integrators $10,11,14$, and 15 and allows them to take on the new best values of $x, y, z$, and the performance measure $\mathrm{f}(\mathrm{x}, \mathrm{y}, \mathrm{z})$. Integrators 7,16 , and 17 are used to prevent updating the parameter values during a compute cycle. The parameters a re updated in Summers 8, 12, and 18 only during the IC cycle. Relay 1 is operated from the IC bus and is used to insure parameter storage in Integrators 10,11 , 14 , and 15 during the IC mode.

Since the performance measure is quadratic, large parameter increments could cause oscillation on both sides of the minimum. This problem is relieved by causing a slight drift in the performance measure with Pot $\mathrm{H} 2$.

\section{Results}

Typical results a re shown in Figures 11 and 12 . Figure 11 shows all three variables converging to produce the minimum performance measure. The technique determined the optimum parameter values in 15 to $20 \mathrm{sec}$ regardless of the initial values. 


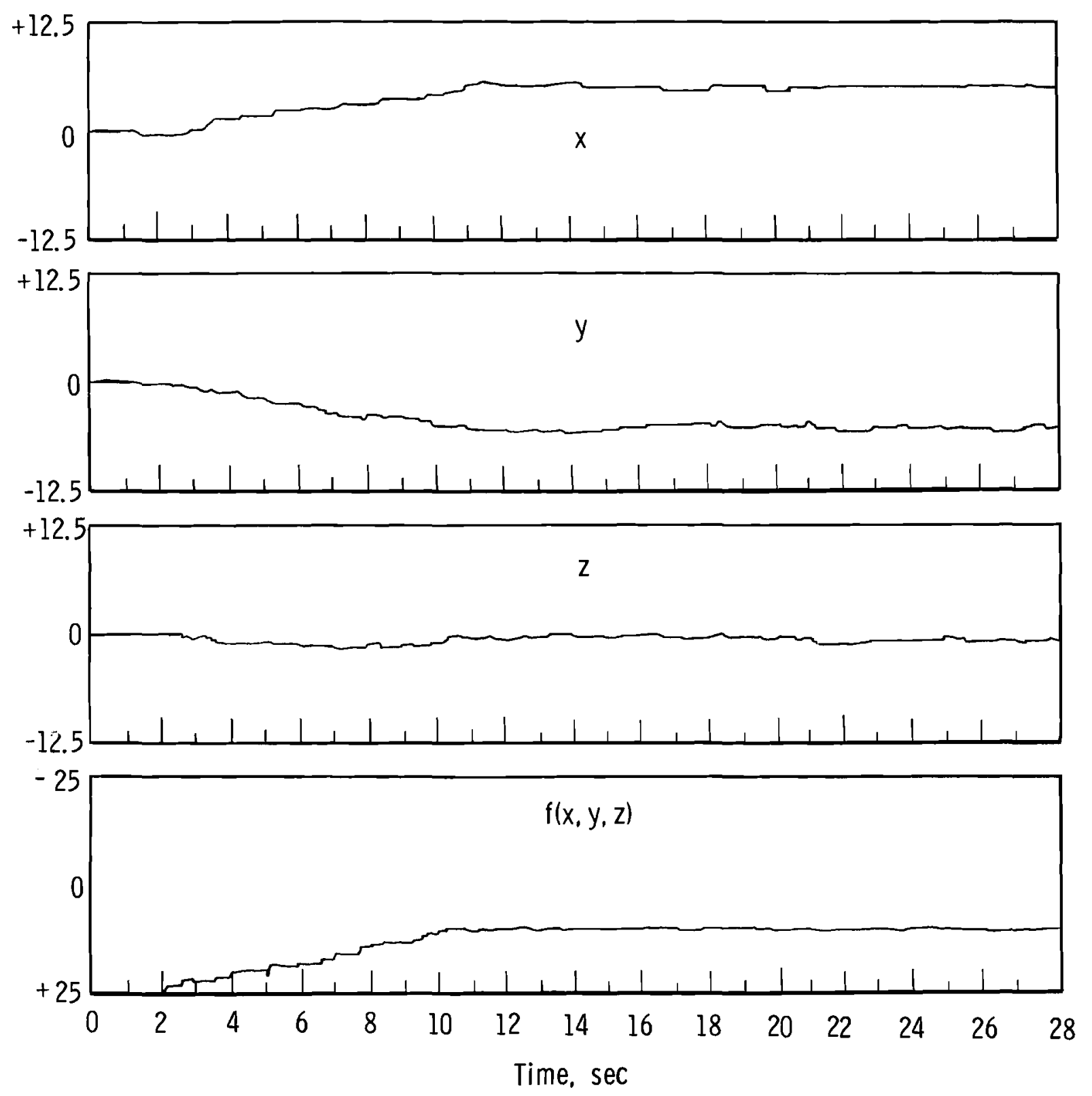

FIGURE 11

Recording of $x, y, z$, and $f(x, y, z)$

Showing Rate of Convergence for Random Optimization Scheme 


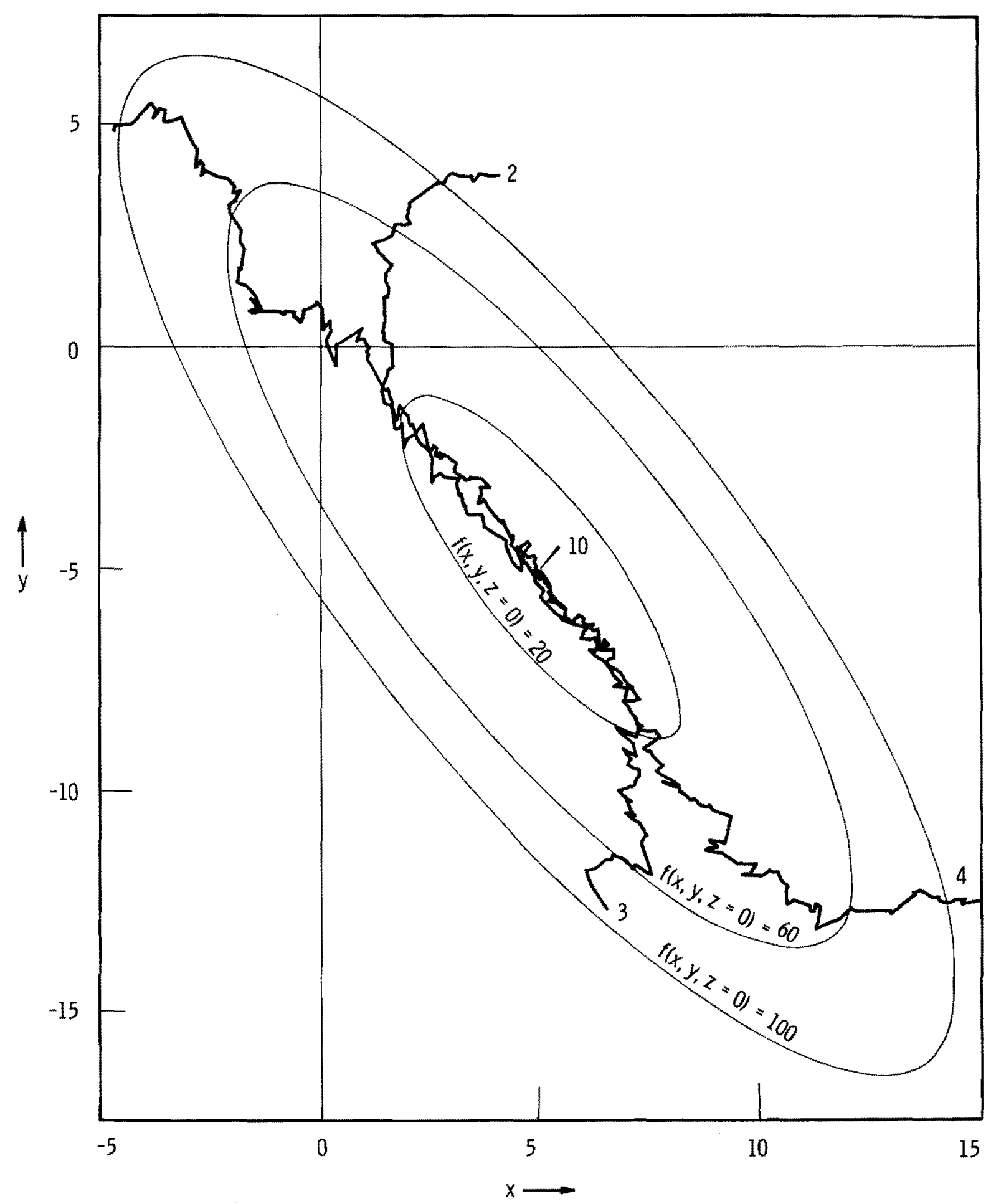

FIGURE 12

Direction of Convergence for Random Optimization Scheme 
To determine the direction of convergence, contours of the performance function were plotted (by the computer) as shown in Figure 12 for $\mathrm{z}=0$. (It is difficult to show gradient direction for a three parameter system on a two dimensional plot.) It is interesting to note that the path taken approaches a steepest descent to the minimum value of $f(x, y, z)$ regardless of the starting point.

\section{Comments}

The use of random perturbations for the optimization of a steady-state system is relatively simple and the results are satisfactory. Random perturbations of the parameters are applied and the performance sampled to determine if the perturbations improved the performance. If the performance is improved, the perturbed values of the parameters are chosen as a new base.

Slight drift in the performance measure is helpful to insure convergence to the minimum rather than oscillating on both sides of the minimum.

For this system the convergence paths approximate lines of maximum gradient change regardless of the starting point.

V. RIVER FLOW: DYNAMIC MODEL FITTING

\section{A. Process Description}

The ability to predict river flow rates at downstream points after step changes in upstream flow rates (i. e., a heavy rain, raising or lowering gates in a dam, etc.) is of interest to hydrologists for flood forecasting. Figure 13 shows a typical plot of flow rates with time at the input and output of a river section. Equation (13), which was derived from standard hydrology equations, ${ }^{(11)}$ is a mathematical model that describes outflow from a given section of a river as a function of inflow.

$$
\frac{d \theta}{d t}=\frac{I-\theta-p k x I^{p-1} \frac{d I}{d t}}{p k(1-x) \theta^{p-1}}
$$




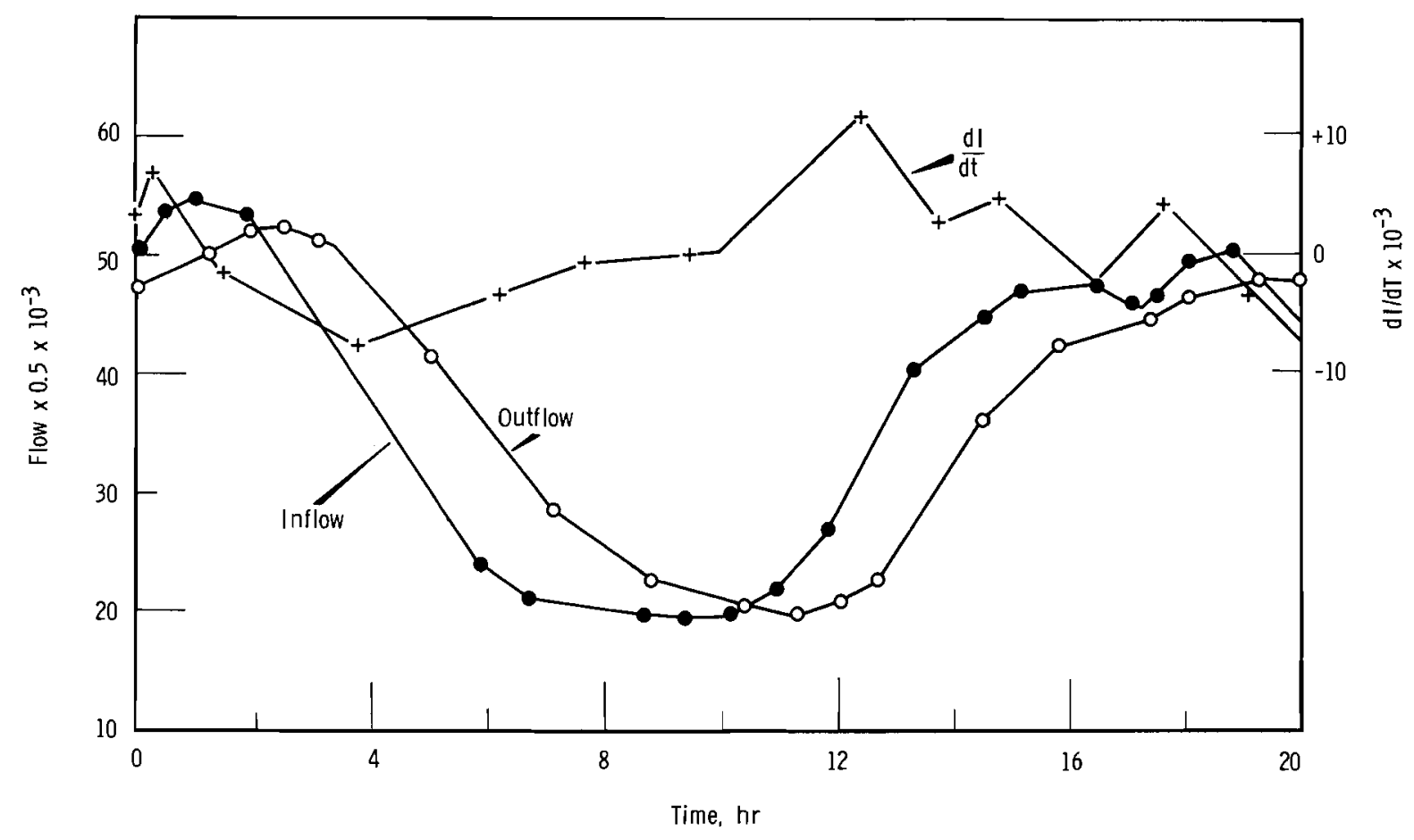

FIGURE 13

Typical Plot of Flow Rates with Time for Input and Output of River Reach

where

$$
\begin{aligned}
& \left.\begin{array}{l}
I=\text { inflow rate } \\
k \\
p= \\
x
\end{array}\right\} \text { parameters } \\
& \theta=\text { outflow rate. }
\end{aligned}
$$

Equation (13) can be used for predicting outflow for a given input function (I) if values of the parameters $p, k$, and $x$ are known. A method of evaluating the parameters is to obtain inflow and outflow data for the given section of the river, then by using the inflow data for an input to Equation (13), the outflow function can be calculated and compared to the outflow data obtained from the river. The values of $p, k$, and $x$ can then be adjusted by hand until the computed value matches the data. 


\section{B. Performance Measure}

The best fit to the data is measured by the error squared integral where the error is defined as the difference between the computed value and the measured value. The values of $p, k$, and $x$ that result in a minimum value of the error squared integral are then the optimum values of the parameters.

As a result of the quadratic form of the performance index, a utomatic computations based on parameter adjustment from value of the error squared integral fail as the minimum error is approached (because it does not change sign) when ordinary feedback technology is used. The partial derivatives, as pointed out by Meissinger, ${ }^{(12)}$ appear well suited for mechanization for automatic optimization of the parameters. The partial derivatives of the performance index with respect to each parameter are equal to zero at the optimum value of the performance index. They also change after passing the minimum value of the performance function.

Precise mathematical evaluation of the partial derivative could prove to be a greater problem than optimizing the original equation parameters. For the river routing model this would be true; however, it depends on the equation. Fortunately, only a measure of the partial derivatives is necessary because the desired solution to the optimization problem occurs when the partial derivatives are zero. The measures of the partial derivative used for this problem are:

$$
\begin{aligned}
& \left(\frac{\partial \int e^{2} d t}{\partial x}\right)_{k, p} \approx \Delta \int_{0}^{t} e^{2} d t \\
& \left(\frac{\partial \int e^{2} d t}{\partial k}\right)_{x, p} \approx \Delta \int_{0}^{t} e^{2} d t
\end{aligned}
$$




$$
\left(\frac{\partial \int e^{2} d t}{\partial p}\right)_{x, k} \approx \Delta \int_{0}^{t} e^{2} d t
$$

The condition that the partial derivatives of the two remaining parameters be constant relative to the other parameters is met by allowing them to vary at three different rates. If the value of $\mathrm{x}$ is allowed to seek its optimum value at the highest iteration rate (about two to ten times faster than $k$, and 10 to 100 times faster than $p$ ), the values of $k$ and $p$ are essentially constant. The optimum value of $\mathrm{x}$ is always present during the iterations for the optimum value of $\mathbf{k}$. Likewise, the optimum values of $\mathrm{x}$ and $\mathrm{p}$ are always used for iterating the optimum value of $p$. Thus, simultaneous optimization of the three parameters takes place.

\section{Automatic Optimization Method}

Figure 14 presents the analog patching diagram for simulating the process equation, and Figure 15 represents the analog program for the optimization scheme.

The logic for the iterative process is described below:

(1) The initial values of $\mathrm{x}, \mathrm{k}$, and $\mathrm{p}$ are inserted as coefficients on Pots 404, 402, and 405 shown in Figure 15.

(2) One solution of the process equations results in a value of the error squared integral (Amplifier 70). This value is tracked and stored in Memory Integrator 65.

(3) A perturbation signal from Pot 403 is used to increment the value of $\mathrm{x}$ by one unit for the next evaluation of the error squared integral. During the IC mode, the value of the previous error squared integral is transferred from Integrator 65 to Integrator 66. During the compute mode, the value of the integral is computed with Amplifier 70 and tracked with Integrator 65. The output of Amplifier 85 at the end of the compute mode is a measure of the partial derivative of the error squared integral with 


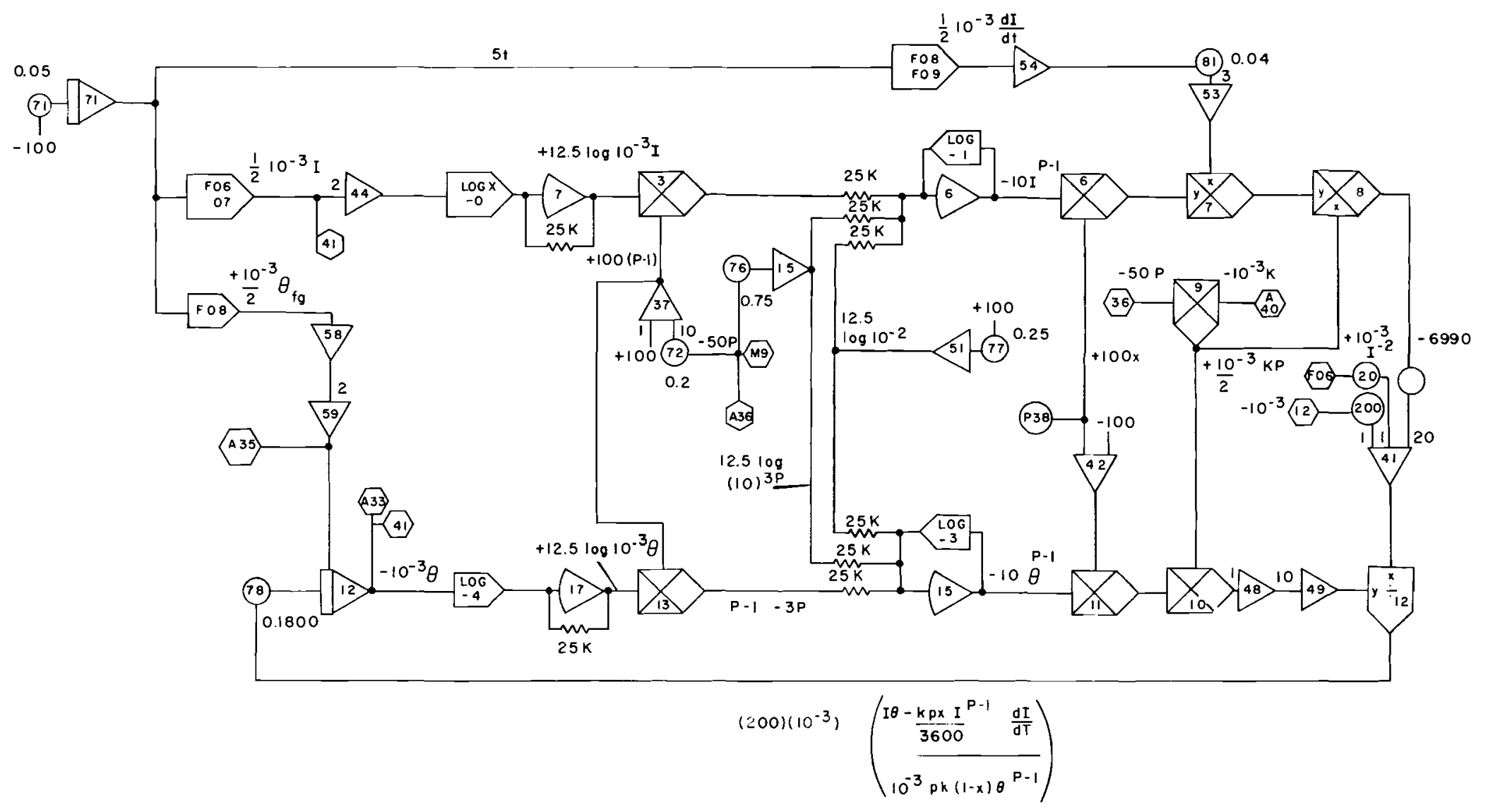

FIGURE 14

Analog Computer Patching Diagram for River Routing Scheme 


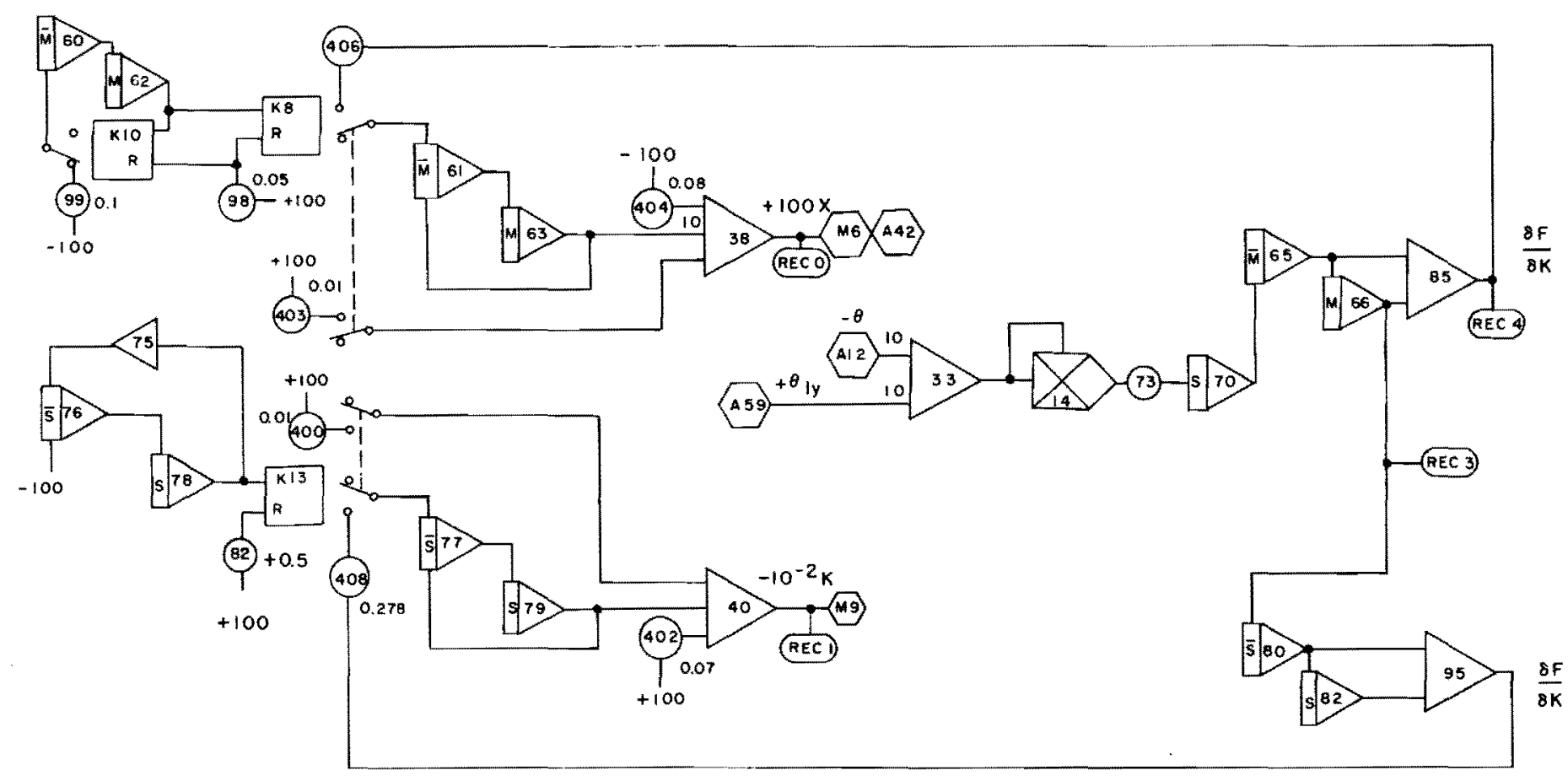

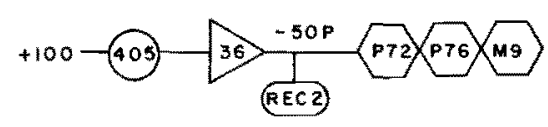

FIGURE 15

Analog Computer Patching Diagram

for the Optimization Scheme 
respect to $\mathrm{x}$. This value is tracked and stored in Amplifier 61 for adjusting the value of $\mathrm{x}$ for the next (third) computation.

(4) For the third solution the perturbation signal is removed and the measure of the partial derivative is used for adjusting the value of $\mathrm{x}$. At the end of the third solution the e rror squared integral is again stored in Amplifier 65. (The switch in the feedback loop will not allow Amplifier 61 to take on the value from Amplifier 85 for the odd number iterative solutions. )

(5) The value of $x$ is once again perturbed with a constant value and the logic discussed in (3) and (4) above is identical. Depending on the gain of the feedback loop this system can converge to the optimum value of $\mathrm{x}$ for the initial values of $\mathrm{k}$ and $\mathrm{p}$ in two to $\mathrm{six}$ iterations.

(6) The logic for adjusting $\mathrm{k}$ is identical to that for adjusting $\mathrm{x}$ except that there are from two to six iterations of $\mathrm{x}$ for every iteration of $\mathrm{k}$. The result is that for a given value of $\mathrm{k}$ and $\mathrm{p}$ the value of $\mathrm{x}$ is optimized.

(7) The logic for adjusting $\mathrm{p}$ could be similar to that of $\mathrm{x}$ and $\mathrm{k}$. However, only two timing units were available for providing the iterative timing. Therefore, the value of $p$ was adjusted slowly by hand with a pot at a rate such that the values of $\mathrm{x}$ and $\mathrm{k}$ were always optimized. The optimum values of the constants were determined when the overall minimum of the error squared integral was found.

\section{Results}

Early results indicated a strong coupling interaction between $\mathrm{k}$ and $\mathrm{p}$. In general, a value of $\mathrm{p}=1$ was found to produce the best values of $\mathrm{k}$ and $\mathrm{x}$. Acceptable fits to the data can be obtained for values of $p$ ranging from 0.98 to 1. 02. Therefore, the results of the simulation show that the customary simplifying assumption $p=1$ is justified. Figure 16 shows the interactions 


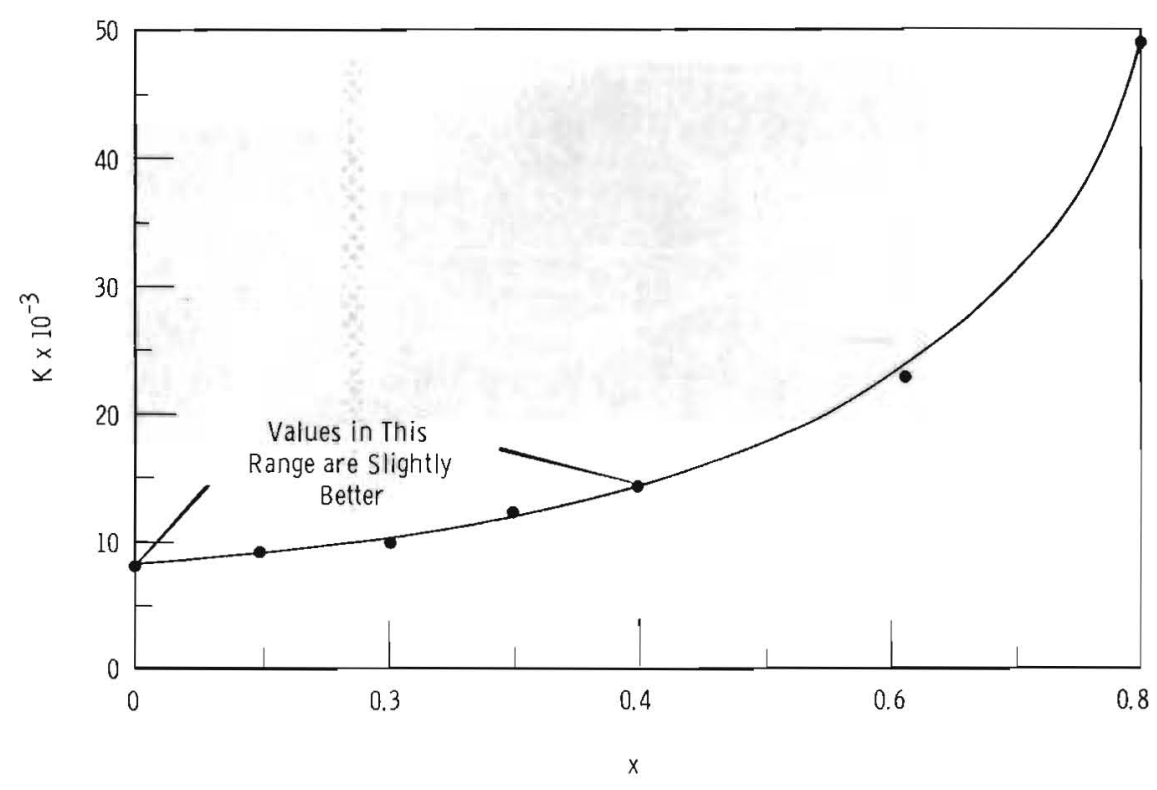

FIGURE 16

Optimum Values of $\mathrm{k}$ and $\mathrm{x}$ for $\mathrm{p}=1,0$

between $\mathrm{k}$ and $\mathrm{x}$ for the value of $\mathrm{p}=1$. Figures 17 and 18 are traces showing comparisons of the measured value of outflow with the computed value of outflow. The series of straight line segments shown in Figure 17 is the measured outflow and the smooth curve is the computed value. The values of $\mathrm{x}$ and $\mathrm{k}$ initially chosen resulted in a poor fit; however, the automatic optimization circuit selected the optimum values of the parameter which resulted in the close fit shown in Figure 18. Figure 19 shows graphs of $\mathrm{x}$, $\mathrm{k}, \mathrm{p}$, and the error squared integral as a function of time.

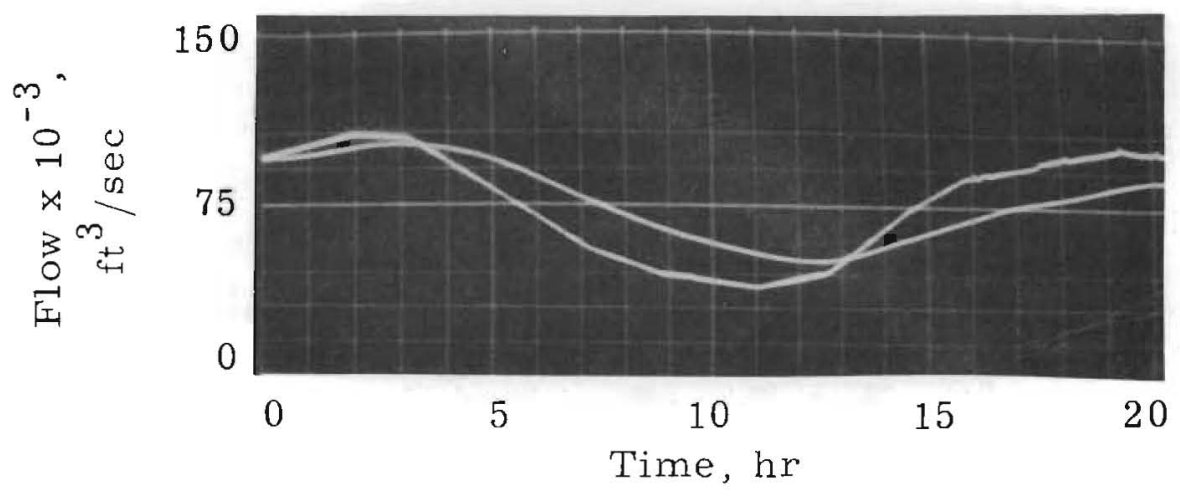

FIGURE 17

Photograph of Oscilloscope Tracing

Showing Initial Fit 


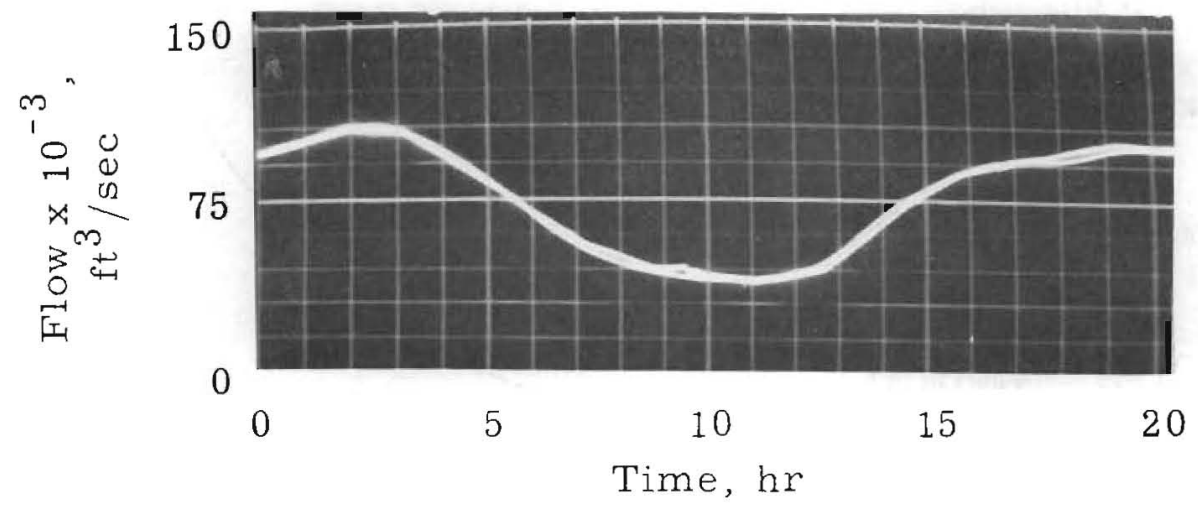

FIGURE 18

Photograph of Oscilloscope Tracing Showing Optimum Fit
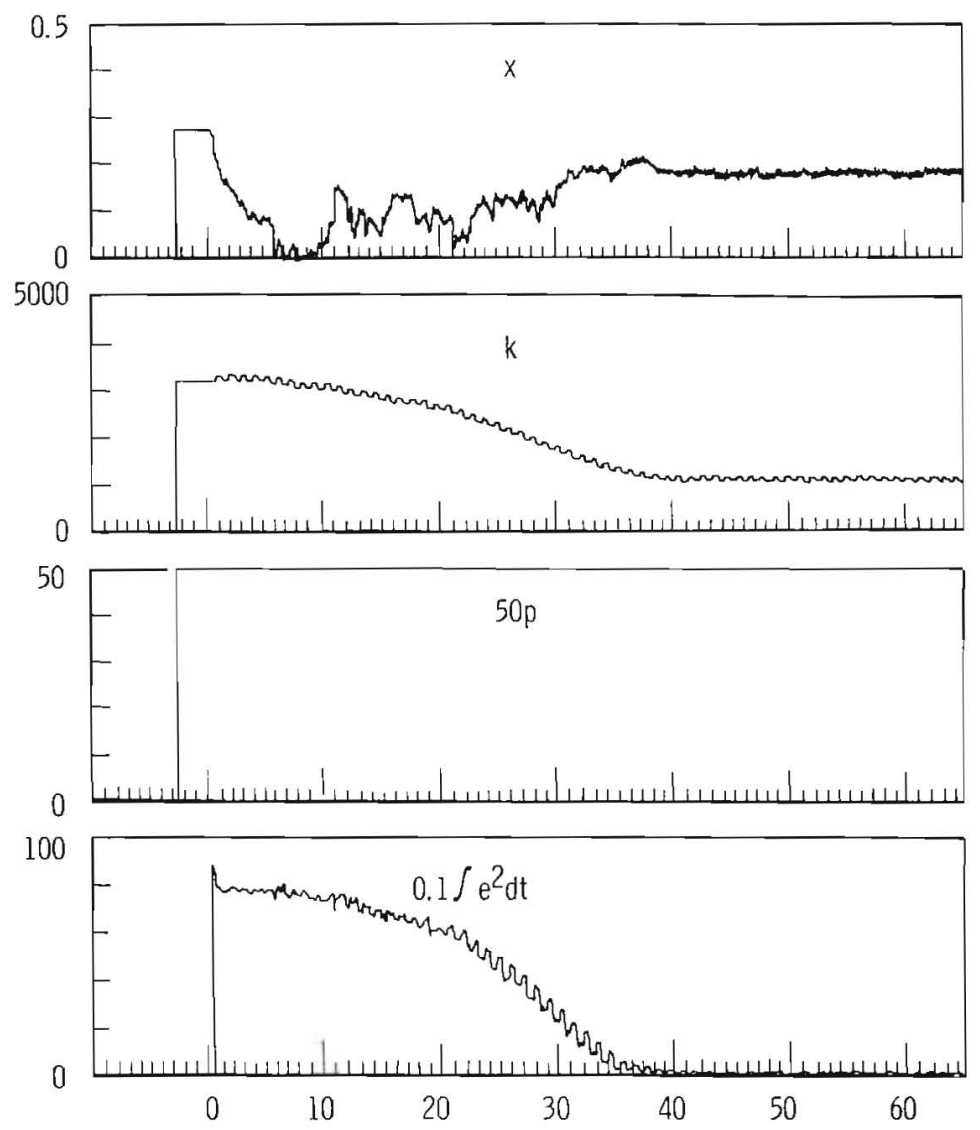

Time, sec

FIGURE 19

Recording of $\mathrm{x}, \mathrm{k}, \mathrm{p}$, and the Error Squared Integral with Time Showing Rate of Convergence of Optimization Scheme 
Figure 19 shows that the optimized value of $x$ was changing about four times faster than $\mathrm{k}$ while $\mathrm{p}$ was held equal to one. After about $40 \mathrm{sec}$ of computer time, the optimum parameters were selected; however, the optimization scheme continued to perturb the parameters away from optimum values.

\section{E. Conclusion}

The methods used in this example appear general in nature and applicable to a wide variety of problems. A quadratic performance index was used, thus straightforward servomechanism feedback techniques could not be based directly on the performance criteria index. Every other computing cycle was used to perturb a parameter of the system so that measures of parameter influence coefficients were determined which served as the feedback signal so that ordinary servo feedback techniques could be used. The principle of optimality was applied in that for the slower changing parameters, the faster ones were always maintained at their optimum values. Figure 14 indicates the number of timing devices required is the same as the number of interacting parameters being optimized. The master (M) and the slave $(\mathrm{S})$ timing devices were used to determine the parameter influence coefficients for the performance as functions of $x$ and $k$. The utilization of timing devices in this manner assumes that the parameters are interacting. If it turns out that the parameters are not interacting in any particular problem, then the problem is essentially one of a number of single parameter problems, and is straightforward. On the other hand, if the parameters are $100 \%$ interrelated, then the number of parameters can be reduced. This was the case of the parameter $p$ in the region of the optimum for the particular problem. 


\section{$\underline{\text { REFERENCES }}$}

1. W. C. Franke, B. B. Gordon, and A. B. Clymer. A Survey of Optimization Methods and Their Applications in Science and Engineering, SARE Catalog no. IV-F-6-1.

2. G. A. Bekey, "Optimization of Multi-Parameter System by Hybrid Computer Techniques-Part II," Simulation, vol. 2, no. 3, pp. 21-29. March 1964.

3. G. A. Bekey. "Optimization of Multi-Parameter Systems by Hybrid Computer Techniques-Part I," Simulation, vol. 2, no. 2, pp. 19-32. February 1964.

4. E. S. Lee. "Optimization by Pontryagin's Maximum Principle on the Analog Computer, "Fourth Joint Automatic Control Conference (sponsored by AIChE). June 19-21, 1963.

5. H. L. Steinmetz. "Using Pontryagin's Maximum Principle to Solve One-Dimensional Optimization Problems with and Without Constraints, on an Iterative Analog Computer (To be published in $\underline{\mathrm{J}}$ of Franklin Institute).

6. H. S. Witsenhausen. "A Heuristic Approach to the Maximum Principle," Simulation, vol. 2, no. 6, pp. 25-30. June 1964.

7. N. P. Wilburn. Mathematical Determination of Concentration Profiles in Two Phase Continuous Counter Current Extractors, HW-SA-3139. General Electric Company, Richland, Washington, August 7, 1963.

8. W. D. Cameron and G. R. Taylor. "Examples of Analog Computer Applications in Nuclear Processes," Simulation, vol. 2, no. 4, pp. 34-36. April 1964.

9. R. D. Benham and N. P. Wilburn. Analog Computer Simulation of a Pulsed Extraction Column, HW-83818. General Electric Company, Richland, Washington. September 1, 1964.

10. J. K. Munson and A. I. Rubin. "Optimization by Random Search on the Analog Computer," IRE Trans. on Electronic Computers, vol. EC-8, no. 2, p. 200. June 1959.

11. O. E. Meinzer. Hydrology, McGraw Hill, New York, 1947. 1st ed., pp. 564-567.

12. H. F. Meissinger. "The Use of Parameter Influence Coefficients in Computer Analysis," Simulation, vol. 3, no. 2, pp. 52-63. August 1964. 


\section{ONSITE DISTRIBUTION}

Copy Number

Pacific Northwest Laboratory

1

2

3

$4-8$

9

10

11

12

13

14

15

16

17

18

19

20

21

22

23

24

$25-34$

35

36

37

38

39

40

41

42

43

44

45

46

47

48-52

53

54

55

56

57

58-62

63

64

\section{F. W. Albaugh}

E. R. Astley

J. M. Atwood

R. D. Benham

C. A. Bennett

R. E. Burns

L. K. Bustad

L. J. Chockie

J. R. Clark

C. R. Cooley

J. R. Corley

K. D. Coughren

F. G. Dawson

P. J. Dionne

G. E. Driver

M. D. Erickson

E. A. Eschbach

W. D. Felix

J. C. Fox

G. F. Garlick

R. A. Ha rvey

R. J. Hennig

B. M. Johnson

A. R. Keene

B. L. Morgan

R. W. Nelson

R. S. Paul

A. M. Platt

L. T. Pedersen

J. T. Russell

J. C. Spanner

W. G. Spear

W. H. Swift

C. D. Swanson

G. R. Taylor

G. G. Thieme

M. T. Walling

R. G. Wheeler

N. P. Wilburn

D. C. Worlton

Technical Information Files

Technical Publications-300 Area

Technical Publications-700 Area 
ONSITE DISTRIBUTION (contd)

Copy Number

General Electric Company, Richland

65

66

67

68

69

70

71

72

73

74

75

76

77

78

79

80

81

82

83

84

85

86
D. L. Condotta

O. D. Erlandson

W. L. Godfrey

O. H. Greager

L. T. Hagie

H. H. Hopkins

R. E. Isaacson

J. E. Kaveckis

H. R. Kosmata

D. W. Leiby

M. C. Leverett

W. M. Mathis

L. R. Michels

H. P. Shaw

P. W. Smith

R. E. Tomlinson

R. E. Trumble

R. A. Watrous

GETA File Copy

$\underline{\text { Richland Operations Office }}$

R. K. Sharp

Technical Information Library

Vitro Engineering Company, Richland

L. D. Lash 